\title{
Rites of Passage or Exploitation? Teaching Social Anthropology, Class Relations and Institutional Change in Two British Universities ${ }^{1}$
}

\author{
Robert GIBB (University of Edinburgh)
}

In this paper I discuss my experience of teaching and researching in two different British universities in the late 1990s in order to develop a number of arguments about the place of teaching in the making and un-making of professional / academic anthropologists. Not all of the issues I raise, however, can be formulated as questions of 'boundaries' or 'identities' (in the way the title and rubric of this panel suggest ${ }^{2}$ ), although for some of them this is indeed appropriate. Thus, while it is true that the nature of disciplinary borders and identities emerge as key concerns, my material also draws attention to contemporary employment and managerial practices in higher education, as well as to the reproduction of various forms of social division (notably along class lines). As the rubric of this panel recognises, it is in fact the re-organisation of sets of hierarchical social relations characterised by domination and exploitation which often lies behind current changes in higher education (as in other social fields). In my view, the boundary concept is not the most useful tool with which to analyse such processes, and in particular the power relations and structural inequalities involved. For

\footnotetext{
1 This is a slightly modified version of my contribution to a paper presented jointly with Jonathan Skinner (University of Oxford and University of Abertay, Dundee) under the title 'Backdoor Anthropology: Teaching and Research Experiences in the "New" Universities and their Disciplinary Implications' at the event 'Teaching Rites of Passage: A Workshop for New Lecturers in Anthropology' held at the University of St. Andrews, 10-11 January 2003. I am grateful to Jonathan Skinner for his comments on the paper. I take sole responsibility, however, for the views here expressed.

2 In the workshop programme, the title of the panel in which this paper (in its joint version) was originally presented was listed as 'Boundaries'. The following note also appeared: 'In this panel we use anthropological skills to explore the interplay of classroom, disciplinary and institutional identities. Papers address the race, gender and status hierarchies within higher education, and how these effect individual teachers and practitioners.'
} 
this reason, I will refer instead to social divisions and status hierarchies in the section of the paper that deals with these wider issues.

\section{Rites of Passage, Teaching and Research}

'Teaching Rites of Passage' - the title of this workshop plays suggestively on the different possible interpretations of each of its terms, and on the various ways in which these can be combined, in order to raise important questions about the relationship between teaching and professional status or recognition as an (academic) anthropologist. On the one hand, it alludes to the argument presented in the call for papers that ' $[\mathrm{t}]$ he first experience of teaching is a key rite of passage in the process of becoming an academic anthropologist'. This is a statement which, on the basis of my own experience, I will suggest nevertheless requires some qualification. It is perhaps also worth noting at the outset that the reference here is to teaching experience effectively abstracted or considered separately from particular types of institutional position or employment contract. The nature of the latter is, I will argue, often a more important factor in the 'passage' to the status of professional, academic anthropologist than the mere fact of having taught social anthropology at some level. On the other hand, the workshop title encourages us to examine the rites of passage involved in becoming a teacher (of social anthropology or any other discipline), concurrently with or after those linked to recognition as a researcher, notably ESRC-sponsored methods / training courses and the completion of a doctoral thesis. Teaching experience in this case is less a means to an end, i.e. becoming a professional or academic anthropologist, than an end in itself; being a teacher is the position or situation to which the rite of passage leads rather than that which constitutes the rite of passage in the first place.

The suggestion here is, then, that applying the classical anthropological notion of rites of passage to the process of becoming a 'professional' or 'academic' anthropologist is a useful 
way of beginning to think about the transition (or not) from graduate student to appointed lecturer. It may be worth pausing briefly, before discussing my teaching experience in detail, to reflect a little further on the appropriateness of the category 'rite of passage' in relation to the professional career of a (social) anthropologist. What are the bare bones of the argument which van Gennep puts forward in his classic 1909 text? As any first-year student of social anthropology knows, van Gennep defines rites of passage as 'ceremonies whose essential purpose is to enable the individual to pass from one defined position to another which is equally well defined' (1960: 3). He argues that these can be subdivided into rites of separation, transition rites and rites of incorporation, although he acknowledges that 'in specific instances these three types are not always equally important or equally elaborated' (1960: 11). Subsequent chapters of his book deal with the various ritual ceremonies which are associated around the world with birth, childhood, puberty, marriage, pregnancy and death.

It is not difficult to classify the various activities associated with becoming a professional / academic anthropologist - the passage from the 'defined position' of 'student' to that of 'lecturer' or 'anthropologist' - in terms of at least two of these subcategories. Most obviously, perhaps, the tutorial or seminar teaching which many doctoral students undertake could be viewed as a process of initiation (with its appropriate rites or 'ceremonies', in this case induction or training sessions) marking the transition from pedagogical puberty to (potential) adulthood. Research methods courses and doctoral fieldwork would be the equivalent initiatory or preparatory experiences in the making of a researcher. Similarly, it would be possible to describe induction sessions, staff meetings and 'away days' as rites of incorporation for newly appointed lecturers, the thesis viva and graduation ceremony symbolising the incorporation (or otherwise) of an individual into the 'research community'. In comparison, rites of separation in the fields of both teaching and research appear much less 'important' or 'developed' (or less readily identifiable). As van Gennep makes clear in the 
second passage quoted above, however, we should not necessarily expect rites of separation, transition and incorporation to be equally significant in practice. Teaching rites of passage would seem to provide a good illustration of this point.

The classification of rites of passage elaborated by van Gennep can, therefore, be used as a convenient framework within which to analyse the process of becoming an academic or professional anthropologist in the sense of identifying the various stages and 'rituals' involved. This has a certain immediate attractiveness and plausibility which I would not wish to deny. Nevertheless, I would suggest that it is potentially more interesting to consider how van Gennep's work can be used for purposes of critique rather than simply categorisation, and also to reflect on the aspects of the process of becoming a professional anthropologist which the notion of rites of passage only partially illuminates. I will give one example of each of these before moving on to the main section of my paper.

An obvious way in which van Gennep's argument can be applied (no doubt against the spirit of its original formulation) in a more critical fashion is through the proposition that most, if not all, of the induction sessions, training courses and other transition or incorporation rites associated with teaching and research are primarily 'ceremonial' in nature. By this I mean that they are often experienced (leaving aside for the moment the intentions of those who devise them) as formal and relatively pointless exercises, attendance at which is often required by employers / supervisors but which rarely provide relevant training or knowledge. As a result, they are often regarded by those involved (on both sides) as mere 'formalities' which have to be observed if you want to get on in your career (we console ourselves with the thought that 'I can always put in down on my CV'). One of the reasons is perhaps that induction courses for new lecturers or ESRC-sponsored research training courses for doctoral students, to cite the most obvious examples, are usually designed to be taken by individuals 
from across a range of subjects and therefore remain at the level of generalities without addressing issues which are discipline-specific. Their completion may be taken (by those in authority) as a marker of an individual's passage from one status to another, but for how many 'new initiates to teaching and researching' is their actual content more helpful in the long run than informal conversations with supervisors, colleagues or peers?

The potential for a critical use of the notion of rites of passage with respect to teaching and research processes should not, however, lead us to over-state its general usefulness or applicability. In my view, there are important aspects of each which are not best (or fully) analysed in terms of rites of passage. A good case in point is the position of graduate teaching assistants (and temporary lecturers, for that matter). On one level, their status and the 'ceremonies' surrounding it could be described as transitional, in line with van Gennep's characterisation of transition rites as 'intended to show that at the moment in question the individual does not belong to the sacred or to the profane world; ... he [sic] is therefore isolated and maintained in an intermediate position, held between heaven and earth, just as the deceased on his bier or in his temporary coffin is suspended between life and true death' (1960: 186). In more secular terms, the graduate teaching assistant (or temporary lecturer) could thus be regarded as occupying a position intermediate between 'student' and 'lecturer / anthropologist', belonging at the same time to both worlds and to neither.

The problem with such a view is that it tends to consider the position of graduate teaching assistants only with respect to an individual's transition from one 'defined' status to another within a professional career structure. In so doing, it draws attention away from the fact that graduate teaching assistants (and temporary lecturers) also constitute a precarious, exploited and marginalized category within the academic division of labour, rather than simply occupying an 'intermediate' (this assertion is itself contestable) position in the status 
hierarchy. It can be argued, in other words, that the existence of what is effectively a reserve army of labour within the higher education sector performs valuable social and economic functions both for universities as increasingly commercialised institutions within late capitalist societies such as Britain and for permanent, full-time lecturing staff within social anthropology departments. A focus on individual or collective 'rites of passage' (or for that matter on 'institutional cultures') runs the risk of exoticising and de-politicising exploitative social relations unless it is accompanied by an examination of hiring practices and patterns of institutional restructuring indicative (and constitutive) of an ongoing 'flexibilisation' of labour within British universities. In the next section of this paper I reflect on my own teaching experience in two British universities in order to begin to illustrate (in an undoubtedly sketchy and impressionistic manner) these points.

\section{(De-)Mystification, Class Relations and Managerial Practices}

Taking up a full-time, permanent teaching post in a multi- and inter-disciplinary social studies department in a 'new' university in the north of England provided me with some distance (spatial, institutional, disciplinary) with respect to my earlier experiences as a graduate teaching assistant ('tutor') in social anthropology at the University of Edinburgh. This increased my awareness of the specific sociological characteristics (in terms of class and ethnicity) of the first-year students I had tutored in social anthropology at Edinburgh. It also drew my attention to employment practices concerning part-time tutors there which I had previously taken for granted or considered 'natural'.

In the first place, I began to appreciate that teaching as a part-time tutor at Edinburgh and as a lecturer in a 'new' university involved contact with very different types of student, particularly in terms of their background in the class structure of British society, and that this 
manifested itself in important ways in classroom interaction. Most of the students taking the first-year social anthropology course at Edinburgh (either as their degree subject or as an option) were white, private-school educated, middle or upper-middle class women and (some) men with a history of university education in their families. By contrast, the vast majority of the students who I taught in the 'new' university (and, for that matter, my colleagues) came from so-called 'non-traditional backgrounds', a widely-used (stigmatising) euphemism for one or a combination of the following social characteristics: minority ethnic, working-class, 'mature' (i.e. older than 26), disabled, female or the first person in their family to go to university. On a general level, this difference in the sociological profile of the students simply reflects the class-bound nature of the in-take in the 'old' and 'new' universities. However, it does highlight the fact (which seems to attract surprisingly little attention from within the discipline) that social anthropology departments, located almost exclusively in the 'old' universities, tend to draw their students from a very narrow, privileged section of British society (this applies even more in the case of foreign students perhaps). What are the implications of this for 'teaching rites of passage'?

At the University of Edinburgh, I tutored groups of first-year undergraduate students in social anthropology in 1992-3 and 1995-6, before and after fieldwork for my doctoral thesis. On both occasions, only a minority of those in my classes intended to study social anthropology as their degree subject; most were taking the first-year course as an 'outside' or 'third' subject either out of 'interest' or to fill up their timetable. (The first category usually included a few older, working-class Scottish women who had secured a place at university through an access course. However, they often abandoned social anthropology as their degree subject at the end of the first year, changing either to sociology or psychology. This resulted in a decrease in the [already extremely limited] diversity of the future Honours students in social anthropology, in terms of age, class and national background.) The students were also 
disproportionately (with respect not just to the UK population as a whole but also compared to the in-take of other social science disciplines at Edinburgh such as sociology) white, private-school educated, middle and upper-middle class women and men (one of my classes even included a man whose father was an hereditary peer).

My first experience of teaching social anthropology, in other words, was tutoring remarkably homogeneous groups of (generally) quite privileged or even wealthy ${ }^{3}$ students, few of whom had any sort of deep commitment to or interest in the subject. A definite sense of appropriate, or polite conduct, and an obedient respect for 'authority' (although often tinged with condescension - the tutor was after all only a young graduate student, employed part-time and paid by the hour) characteristic of a particular (bourgeois) class habitus ensured that actual classroom interaction passed off relatively smoothly: lack of interest in the subject rarely gave rise to obvious signs of boredom or 'disruptive behaviour', nor did an absence of preparatory reading for the class prevent most students from confidently expressing opinions about the matter under discussion (usually with some reference to their 'gap year' between school and university, which many had spent overseas). It could be argued that although not particularly challenging or stimulating, intellectually and pedagogically, such teaching was in certain respects at least quite 'easy' (even though as a neophyte it may not have felt so at the time).

In comparison, lecturing in Sociology and then European Studies at a 'new' university in the north of England in the late 1990s was a much more 'testing' experience, and at times seemed to involve elements of an 'initiation rite' (although the underlying stake was the imposition and contestation of various forms of social hierarchy and power relations both within and outwith the classroom). A colleague with whom I shared an office remarked to me soon after

\footnotetext{
${ }^{3}$ On one occasion before a class I overheard a first-year student complain to her neighbour about the number of parking fines she had received in her first few months in Edinburgh. As well as being struck by the fact that she could afford to run a car, I was amazed that the amount in fines which she had to pay was more than the salary I was earning as her tutor for the whole term.
} 
I first arrived: 'If you can teach here, you can teach anywhere!' Knowing that I had moved down from the University of Edinburgh, he was keen to point out that the students I would now be teaching came from much less privileged backgrounds and that as a result my experience in the classroom was liable to be somewhat different (the implication being that it would be more difficult). In the event, many of the problems I encountered are found within higher education more generally and are not specific to particular institutions or groups of students. The most basic of these were poorly-equipped teaching rooms, insufficient copies of books and articles in the library for the number of students on a given course, the time needed for new material to appear on the shelves (due to library under-staffing), and students' lack of reading and preparation. What differed most significantly from the situation at Edinburgh was perhaps the extent to which the last of these was attributable to the fact that many students were attempting to complete a degree course while simultaneously working part- or even fulltime to support themselves and / or their families.

The nature of actual classroom interaction with students was broadly similar in both institutions, except in one important respect. Compared to the first-year undergraduate students I tutored at Edinburgh, those at the 'new' university where I was a lecturer were more prepared openly to question not only how I taught them but also my qualification to do so, i.e. the legitimacy of my position as a teacher. This took both direct and indirect forms. On the one hand, working-class and Black or Asian students would ask me, in class or during office-hour conversations, whether it was appropriate for a white, middle-class man to be lecturing them (often minority ethnic, working-class women) about issues such as poverty, class relations, sexism and racism. On the other, students dissatisfied with aspects of my teaching would not raise their concerns personally with me, but instead go directly to a senior colleague and complain to them. Rather than suggesting to the students that they should take up the matter directly with me in the first instance, the colleagues in question often reacted by 
attempting to resolve the issue themselves, which usually only complicated the situation still further. (Such challenges to my position or 'authority' as a teacher never occurred while I was a tutor at the University of Edinburgh, but it is not clear to me whether [and if so, how] this can be explained by the difference in institution or in my status.)

Following on from this last point, I would argue that it was in fact relations with other colleagues rather than the students which proved to be the more constant source of frustration, pressure and anxiety over the four-year period during which I taught at a 'new' university in the north of England. As a new lecturer, I soon came to realise that I had need of 'survival techniques' not so much in the classroom as in the staff-room. The induction course for new members of staff which I attended when I joined the university did not equip me, for example, to deal with colleagues who sought systematically (and in ever more ingenious ways) to undermine my position, who were deliberately and needlessly obstructive or who simply refused to acknowledge me when we passed each other in the corridor.

Underlying such reactions, in my view, was an unresolved tension between research and teaching (and between researchers and non-researchers) which probably existed in many other 'new' universities as well during the 1990s. This was the period that witnessed the transformation of the former Polytechnics into 'new' universities, involving both an expansion in student numbers and an increasing, RAE-driven emphasis on research 'output' within institutions whose traditional role had primarily been the provision of applied or vocational training. Those appointed to the new posts which were created as part of this development tended (not only, I suspect, in the institution where I was employed but elsewhere too) to be young academics having just completed or about to finish a $\mathrm{PhD}$.

While student numbers continued to grow across the sector, the influx of a cohort of young lecturers did not in most cases generate significant tensions: on the contrary, it was often 
viewed positively by hard-pressed existing staff confronted with ever larger classes to teach and by university managers keen to raise the 'research profile' of their institutions. However, students numbers began to fall in many of the 'new' universities towards the end of the decade, as it became increasingly apparent that the latter were losing out in the competition to attract students - and consequently, potential funding - with the older universities (who had only, for example, to lower their entrance requirements to draw students who would previously have applied to the former Polytechnics). This led in turn to university managers insisting on the need to address 'over-staffing' through departmental restructuring, 'redeployment', early retirement, and voluntary (and implicitly also compulsory) redundancy - to attempt in other (management-speak) words to 'lose' staff.

Administrative staff were the first to suffer the consequences, but in time academic staff also began to be affected. At the institution where I was employed, a number of 'audits' were carried out which sought to identify, on the basis of shifting criteria ('student numbers' nevertheless remaining the principal one), areas or subjects perceived to be 'at risk'. Initially presented as a one-off response to a particular crisis, such audits developed into annual or even more frequent exercises of managerial control which had the effect of maintaining a fairly constant pressure on (all) staff and contributing significantly to a general climate characterised by fear and a rising sense of job insecurity. Not surprisingly perhaps, fault-lines started to appear, not only between administrative and academic staff but also between members of the teaching staff classified as being or not being 'research-active'. ${ }^{4}$ In such a context, teaching staff involved in research, and particularly the relatively young lecturers

\footnotetext{
${ }^{4}$ When I first arrived at the institution the use of titles such as 'Dr' or 'Professor' was regarded as 'elitist' or 'divisive' and so name-plates on office doors only carried a person's first and second names. After several years, however, and in response to the growing importance which university managers attached to participation in the RAE and to research activity as key to improving the institution's 'image', it was decided that titles should appear on these name-plates. The obvious result was to accentuate and give visible form to status differences between colleagues.
} 
recruited in the early to mid-1990s who had the additional 'advantage' of 'costing' the institution less in salary terms, often came to be perceived by their other colleagues (and not without some foundation, it has to be said) as enjoying a more secure position by virtue of their potential contribution to the university's RAE submission.

This could lead to feelings of resentment or hostility, which on occasion might be openly expressed. A division between 'research' and 'teaching' was particularly pronounced in the Department where I taught European Studies in my final year at the institution. Targeted by university managers as a result of a dramatic fall in student recruitment to modern languages and European studies courses (reflecting national trends), relations became increasingly tense between, on the one hand, those engaged in research and able to be entered for the RAE (less than a third of the department) and, on the other, the rest of their beleaguered colleagues. The raising of research-related issues at staff meetings would provoke reactions of more or less muted anger or hostility from other colleagues, and comments were made on a fairly regular basis which implied a view of 'researchers' as a privileged group of self-obsessed and selfish prima donnas unwilling to do their 'fair share' of teaching (the elitist attitudes of some but by not means all 'research-active' staff only appearing to confirm this perception).

The scheduling of meetings became a recurrent issue between, on the one hand, staff keen to keep one or two days 'clear' each week when they could work at home or in other university libraries on their research (or, in the case of new lecturers, prepare their teaching in a quieter environment than an office shared with one or two other colleagues) and, on the other, those of their colleagues who assumed that all staff should be 'in' (i.e. working in their offices at the university) every day, within 'normal office hours' (i.e. from 9am to 5pm). Arriving at work after 10am or not being 'around' two days in a row would result in pointed remarks from administrative staff and other colleagues, often but not always in the form of jokes (a 
good example of the way in which jokes can be used to draw attention to the perceived transgression of dominant social norms). In the course of one angry exchange (in the corridor, with students milling past) about the timing of a meeting, for example, a colleague said to me 'But you are a full-time member of staff, aren't you?', to which I retorted, almost without thinking, 'Yes, but $I$ do research!'

Thinking about this incident at home later that same day, I was shocked by (and ashamed of) the way I had defended myself from a perceived attack on the part of a colleague by invoking my status and activity as a 'researcher' with such a sense of superiority. ${ }^{5}$ I was struck by the extent to which the distinction between 'researchers' and 'non-researchers' had become a kind of departmental lightning rod, ensuring that very real anger and frustration - my own included - was directed toward other colleagues (subject to exactly the same pressures and concerns about their professional future) rather than at the university managers (from the Head of Department upwards) or the educational policies of the New Labour government. At a time when it was rumoured that the university management wanted to 'lose' ten members of staff within the department - rumours playing a key role in destabilising relations between colleagues and fostering a general climate of fear at the institution - the development of an increasingly tense relationship between 'researchers' and 'non-researchers' was rendering workplace solidarities more fragile and preventing recognition of the common interests of all members of staff in the face of thinly veiled management threats of future redundancies.

The accentuation of a division between 'researchers' and 'non-researchers', which I have suggested here can be understood largely as a response to increasing job insecurity and management concerns about 'falling student numbers', was a key factor shaping my experience of teaching and research at the 'new' university where I worked from 1996-2000. 
I have argued that the roots of this division lie in the role historically played within higher education by the former Polytechnics and the ways in which university managers responded to first an expansion and then a reduction in student numbers over this period in the context of a more general transformation of these institutions into 'new' universities. It seems unlikely that a similar process could have occurred in an 'old' university during the same time: not only is there a more established 'research tradition' in such institutions (involving an expectation that all staff are engaged in research, at least in theory), but most of the latter also continued to experience a rise in student numbers throughout the 1990s (generally, as I have pointed out, at the expense of the 'new' universities). New lecturers recruited to 'old' universities in the late 1990s no doubt had to deal with pressures and conflicts of their own but I would be surprised if these were bound up with the simple fact of being a 'researcher' to the extent as was the case in the institution where I was employed.

\section{Conclusion}

In this paper I have drawn on my experience of teaching in two British universities to raise a series of questions (which are only addressed in a very partial and impressionistic manner here) about employment and managerial practices in higher education, the reproduction of forms of social division, and the ways these might impinge on the making and un-making of professional / academic anthropologists. More specifically (and with reference to the theme of the workshop), I have suggested that an analysis of the working conditions and professional situation of 'new lecturers' or graduate teaching assistants in (social) anthropology in terms of 'rites of passage', 'boundaries' and 'identities' is problematic, in the sense that it runs the

\footnotetext{
5 The realisation that I was internalising this kind of elitist attitude toward research was, in combination with a number of other incidents occurring at around the same time and a pressing need to finish my doctoral thesis, a key factor in my subsequent decision to leave the university.
} 
risk of exoticising and de-politicising social relations perhaps more appropriately characterised in terms of exploitation and reflecting the imposition of more 'flexible' employment patterns.

\section{Reference}

Gennep, Arnold van. 1960 (1909). The Rites of Passage (tr. M. B. Vizedom and G.L. Caffee). London. Routledge and Kegan Paul.

Robert Gibb was the Leach / RAI Fellow at the University of Edinburgh in 2001-2002. He is currently working on a research project funded by the British Academy entitled 'Spontaneity' and 'Organisation': Anti-Racist Mobilisation in France During and After the 2002 Presidential Elections. Previously he worked as a 'tutor' while completing a $\mathrm{PhD}$ at the University of Edinburgh, and then as Lecturer in Sociology and subsequently European Studies at a 'new' university in the north of England. 